\title{
Percutaneous Hepatic Perfusion
}

National Cancer Institute

\section{Source}

National Cancer Institute. Percutaneous Hepatic Perfusion. NCI Thesaurus. Code C148433.

A minimally invasive procedure in which high dose chemotherapy is delivered directly to the liver via a catheter placed in the hepatic artery, and the effluent blood returning through the hepatic veins is filtered via an extracorporeal system before being returned through a sheath in the internal jugular vein. 